\title{
Arte e Autoritarismo (entrevista com José Rufino para a série História da ditadura: novas perspectivas) ${ }^{1}$
}

\author{
Art and Authoritarianism (interview with José Rufino for \\ the series History of the Dictatorship: New Perspectives)
}

\section{Arte y Autoritarismo (entrevista con José Rufino para la serie Historia de la Dictadura: nuevas perspectivas)}

\author{
José Rufino* \\ Universidade Federal da Paraíba, Brasil
}

https://doi.org/10.22409/poiesis.v20i34.38537

\begin{abstract}
RESUMO: Entrevista com José Rufino realizada por Paulo Cesar Gomes, na qual o artista aborda sua formação dupla, tanto pela graduação em geologia, mestrado e doutorado em paleontologia pela UFPE, quanto por sua atuação artística transdisciplinar experimental ampliada pela transversalidade entre arte e ciência. Literatura, política e natureza compõem sua poética conceitual, estética e existencial. É desta base complexa de transbordas e invenções de processos plásticos e fenomenológicos, sem deixar de explorar um forte posicionamento político contra a ditadura e tortura "nunca mais", que Rufino abre caminhos para um devir floresta para a escola de arte.
\end{abstract}

PALAVRAS-CHAVE: arte; literatura; política; natureza

\footnotetext{
* José Rufino é artista, doutor em Geociências e professor de Artes Visuais da Universidade Federal da Paraíba e do Programa de Mestrado em Artes Visuais das universidades federais da Paraíba e Pernambuco. E-mail: contato@joserufino.com.
} 
ABSTRACT: Interview with José Rufino by Paulo Cesar Gomes, where the artist discusses his dual education, both by the undergraduate degree in geology, master and doctorate in paleontology at UFPE, as well as by his experimental transdisciplinary artistic performance expanded by the transversality between art and science. Literature, politics and nature make up its conceptual, aesthetic and existential poetics. It is from this complex base of overflows and inventions of plastic and phenomenological processes, while exploiting a strong political stance against dictatorship and torture "never again", that Rufino opens the way for a becoming forest for art school.

KEYWORDS: art; literature; politics; nature

RESUMEN: Entrevista con José Rufino por Paulo Cesar Gomes donde el artista discute su doble educación, tanto por la licenciatura en geología, maestría y doctorado en paleontología en la UFPE, como por su actuación artística transdisciplinaria experimental expandida por la transversalidad entre el arte y la ciencia. La literatura, la política y la naturaleza conforman su poética conceptual, estética y existencial. Es a partir de esta compleja base de desbordamientos e inventos de procesos plásticos y fenomenológicos, al tiempo que explota una postura política fuerte contra la dictadura y la tortura "nunca más", que Rufino abre el camino para convertirse en un bosque para la escuela del arte.

PALABRAS CLAVE: arte; literatura; política; naturaleza

Citação recomendada:

RUFINO, José. Arte e Autoritarismo (entrevista com José Rufino para a série História da ditadura: novas perspectivas). Poiésis, Niterói, v. 20, n. 34, p. 71-86, jul./dez. 2019.

[https://doi.org/10.22409/poiesis.v20i34.38537] 


\section{Arte e Autoritarismo (entrevista com José Rufino para a série História da ditadura: novas perspectivas)}

[00:00 03:49] José Rufino: Eu tenho uma formação que não é em artes. Sou formado em geologia na Universidade Federal de Pernambuco; me formei em [19]89. [...] Fiz mestrado e doutorado nessa área também. Sou paleontólogo de formação. Então, tive uma atuação durante vários anos como cientista, pesquisador dessa área de ciências, enfim, da natureza. Apesar dessa formação que não é em artes, a produção artística me acompanha desde meados dos anos 80 . Eu sou filho de artista, minha mãe Marlene de Almeida é artista, e isso me ajudou a ter essa aproximação com arte. Desde criança convivo com o mundo cultural, principalmente por causa da vida deles; então, a vida da família como um todo, dos dois lados, paterno e materno, por ter escritores como José Américo de Almeida, Horácio de Almeida era historiador, meu tio avô... então, isso era um ambiente muito favorável. Eu fui fazer geologia em Recife em 1983, sabendo que queria isso, gostava muito, mas, ao mesmo tempo, desconfiava que teria paralelamente uma atividade na área cultural, que eu achava que ia ser literatura. Durante o curso nos anos 80, cheguei a escrever poesia, até publicar em uma ou outra cole- 
tânea, organizava algumas coisas na universidade. Só depois que isso vai se transformando aos poucos, eu diria que saiu do papel do texto convencional, passou para uma espécie de poesia visual, arte postal e depois é que isso vai se tornar então desenho. Sempre num suporte ou com um vínculo com a palavra, que eu nunca perdi no trabalho como um todo.

Então, atualmente moro em João Pessoa, sou professor do departamento de artes visuais, tanto na graduação quanto da pósgraduação em artes visuais. Esse é um jogo. Na realidade, levar junto o trabalho de pesquisa na academia e essa vida, digamos, no sistema de artes. Produzindo para atender essa demanda, que é uma demanda que passa pelas curadorias, pelas grandes exposições, que tem um ritmo, tem uma espécie de pressa de acontecer. Isso é bem diferente da pesquisa acadêmica em geral, então, eu sou na realidade um artista pesquisador.

Como artista pesquisador, então, opero no campo da poiésis, ou seja, a voz que emana da própria obra, através do seu autor se torna pesquisa. Então, se eu escrevo sobre o que estou produzindo, isso é contemplado no campo da pesquisa em artes, seria, digamos, a ciência da arte. Mas, ao mesmo tempo, outra coisa paralela vai correndo. Que é essa fora da esfera acadêmica, que tem, digamos, uma imbricação, às vezes, muito mais eficiente, infelizmente, com a sociedade. É como se dentro do campo com a universidade eu poderia sobreviver ali, tendo uma espécie de produção artística que ao mesmo tempo era minha pesquisa e que gerava, inclusive, uma relação com os alunos de pesquisa, de ensino e de extensão. Mas, isso poderia estar completamente desvinculado desse, vamos chamar, "mundo real" da arte e sua relação múltipla e plural com diversos campos da sociedade.

[03:49 12:14] José Rufino: Eu sou filho de preso político, meu pai Antônio Augusto Almeida era secretário do partido comunista aqui na Paraíba, e conheceu minha mãe, Marlene Almeida, exatamente durante essa época, no movimento. Eles eram muito ligados às ligas camponesas; essa função praticamente de fazer a ponte entre um partido e as ligas, no sentido de formação, enfim, levar muitas vezes ao meio rural a possibilidade de uma estruturação de pen- 
samento mais conceitual, digamos, no campo político, essa era a função. Mas, ao mesmo tempo, o pai do meu pai de quem eu uso o nome, José Rufino (avô), era um coronel de engenho, um senhor do coronelismo, a minha família por parte de pai, desde o antepassado primeiro que veio para cá de Portugal, já enveredou diretamente na cultura canavieira, passou a ter engenhos e escravos no interior da Paraíba. Esse antepassado chegou a ter inclusive uma fazenda de criação de escravos, a produção de seres humanos para venda.

Então, essa história está acoplada de forma inevitável na minha história de vida, como se eu tivesse duas maneiras de viver, até hoje, porque não dá para tomar um banho e se livrar de partes do passado da gente. Então, eu tive de crescer com isso, ao mesmo tempo, com os resquícios da opulência e da cultura canavieira. Eu fui menino de engenho ainda, mas, praticamente da última geração. Então, acompanhei a derrocada, a morte do meu avô no final dos anos 70 (1979), e consequentemente a ruína desse quase império que girava em torno dele e de outros semelhantes.
Mas, meu pai já jovem se interessou, enfim, fazendo engenharia civil, pelo lado social, digamos, da atividade de engenheiro. A partir daí, cai no marxismo e começa essa outra trajetória dele... Nunca se desentendeu do pai, isso é incrível. Sempre teve uma relação possível entre eles e, é claro, eu também, dentro do universo da família. Mas, para minha mãe foi muito mais difícil se inserir dentro dessa família que não aceitava um membro que carregava, digamos, uma espécie de perigo e que não se encaixava ali, dentro do que era tido como bom para o ambiente familiar dessa família canavieira.

Minha mãe vem de uma família de funcionários públicos, de gente que tinha pequenos sítios, pequenas propriedades, mas não de latifundiários, enfim, nem de empresários ou de políticos importantes. Então, isso [essa rejeição] para mim virou uma espécie de matéria a ser tratada, enfrentada.

Nos anos 80 eu recebi como herança, digamos, o rescaldo cultural desse José Rufino, desse avô, e terminei me interessando muito por isso, como se a família tivesse que encontrar alguém ali que se interessasse por aquilo que não era uma propriedade, 
que não poderia gerar, digamos, lucro. Acabei herdando isso, a biblioteca, cartas, documentos pessoais e fui fazendo uma espécie de revisão. Então, para mim, naquela época, essa documentação toda era histórica, ou seja, ia organizar cronologicamente a história familiar, também ler e foi isso que aconteceu.

Fui morar em Recife, e lá num apartamento com caixas e caixas de cartas desde o século XIX até meados dos anos 70. Eu comecei a fazer isso, abria as correspondências, organizava por data e separava o envelope, como se fosse encadernar tudo. Entrei em um processo alucinante de leitura de tudo isso, muitas cartas terminavam num pedido de destruição, "destrua após ler", e estavam lá guardadas, de alguma forma eu devassei os segredos familiares.

Entrar no lócus escuros da história da família, inclusive de parentes vivos, tornou minha relação com a família melindrosa, estranha em muitos momentos e, na realidade, para mim terminou funcionando como processo de catarse pessoal, porque muitas questões que estavam ali colocadas por um tio, por exemplo, irmão de meu pai, eram idênticas às minhas e aí parecia que eu ti- nha acabado de perceber que havia uma ciclicidade e que eu era parte de novo de um giro dessa roda. Vou até usar o sentido de roda d'água que era citado por um dos parentes, eu tive de quebrar isso para minha própria sobrevivência, para minha própria existência, diante das histórias tão fortes dos meus pais, essa história tão forte de meu avô e de toda sua família.

Eu poderia ter queimado todo esse acervo, como proprietário material, familiar íntimo pessoal, antes de ser historiador. Mas, por sorte resolvi transformá-lo em outra coisa, em algo que pudesse atuar novamente como se fosse sair de uma cápsula íntima e partilhar aquilo com a cápsula íntima de qualquer pessoa... isso é possível através da arte. Então, eu já sabia disso, já tinha esse interesse e tentei resolver essas questões que seriam da intimidade, o tempo inteiro oferecendo algo que não era mais para mim, tudo isso virou a série Cartas de Areia que eu produzo, então, desde 80 e poucos até hoje, usando diretamente os originais de cartas e envelopes.

Lá por 1990, eu dizia que estava lutando contra a história, como se tivesse dando um basta, fazendo uma espécie de revisão da 
história, como se eu estivesse voltando e de alguma forma tratando, ali, do acontecido. Mas, logo depois eu vi que isso era pura ingenuidade, porque eu estava simplesmente provocando um pequeno desvio, aquilo que iria para um arquivo de uma fundação, enfim, estava indo para um museu de arte, estava caindo de alguma forma em um ou outro formato de história, isso eu logo percebi. Eu não estava destruindo a história e sim acrescentando camadas ali em cima.

Só para lembrar, muitos anos atrás, em uma palestra em Recife, eu estava falando sobre essa série e uma pessoa entrou no auditório; eu não sabia quem era e no meio da fala começou a gritar: "José Rufino, você é um destruidor da história." Aos berros, era Jomard Muniz de Britto que, na realidade, estava me ajudando, atuando ali no momento, colocando tempero, jogando gasolina na coisa, porque na realidade, estava do meu lado e não desse tal trato da história convencional. Então, hoje em dia eu acredito muito mais nisso, em história que é construída entre pessoas com possibilidades de compreensão muito mais abertas, muito mais difíceis, inclusive, de compreender do ponto de vista acadêmico do que a história convencional. Feita em documentos que estão ali parados, não levantam a mão para dizer; "Epa! Não é isso!"

[25:06 42:50] José Rufino: Na verdade, os primeiros trabalhos, assim, que claramente aparece a questão da tortura, começam no comecinho dos anos 90. No começo dos anos 90 eu fiz uma instalação que se chama Lacrymatio, que é como uma árvore genealógica, com tubos pretos, que são cartas de família pintadas de preto, parcialmente cobertas, de onde se desprendem esses tubos. Eles vão todos se juntando e terminam em uma cadeira que tem placas metálicas, como uma cadeira elétrica. Então, é uma fusão aí da história familiar, como se fosse uma árvore genealógica que provoca uma descarga em alguém, certo? E quem é esse alguém? Era meu avô, era esse antepassado português que veio para cá, marinheiro Jorge? Francisco Jorge Torres. Ou eu próprio? Meu pai?

Então, eu fui lentamente nos primeiros trabalhos... usava mais subterfúgios para lidar com o assunto. Porque, para mim também a coleta disso foi feita de forma não só fragmentada, mas apoiada em fantasia. Quando 
você [entrevistador] diz isso, e fala da relação entre memória e esquecimento, o que é que eu tenho em mim que é fantasioso da ditadura? Ou foi um fato real? Não interessa, não importa, porque, na realidade, se eu fantasiei, isso passa a ser um caso concreto para mim. Gerou as consequências, então, por exemplo, o pavor, o pânico e o medo. Então, é concreto!

É por isso que quando a gente fala de comissão da verdade, fica tão difícil ponderar. Então, qual é o peso? A sua dor é mais forte que a do outro? "Ah, eu fui torturado. O outro imaginou que foi." E aí? Certo? Então, são essas questões que eu tive de alguma forma criar lugar, espaço para isso e usar no trabalho.

Eu já sabia em meados dos anos 90 que queria enfrentar mais isso, de vez. Mas, tinha essa... Isso que eu digo a você, quase uma proibição da minha geração e eu esperei um pouco, porque também, precisava amadurecer, inclusive, criar um pouco de força e de coragem para atuar. E no final dos anos 90, eu já sabia que produziria uma obra politicamente mais contundente, sobre - eu achava que era -, sobre minha relação de criança com essa figura que me assustava que eu não sabia exatamente de onde vinha, como se fossem figuras como "papa figo", "bicho papão"... eu confundia isso quando criança, com um possível atentado de militares ou da polícia, enfim, eu não sabia de onde viria.

Então, eu não entendia bem o que era o "bicho papão", ou se ele andava com roupa de militar, então, isso para mim era a mesma coisa. No ano de 2001, eu fui convidado para participar da Bienal de São Paulo, pelo Agnaldo Farias. Lá em São Paulo, em uma estadia minha lá, ele fez um convite livre e eu que sugeri ter esse trabalho que estava de alguma forma latente, sobre a ditadura. E ele disse: tudo bem, vamos fazer. Eu desencadeei o processo, foi muito rápido, porque é como se a ditadura estivesse presente na minha cabeça. $O$ desejo inicial era que o trabalho fosse sobre saudade, uma sensação assim, de saudade que eu percebia que estava, por exemplo, nos meus pais, a saudade de companheiros perdidos, desaparecidos, alguns nessa época tinham reaparecido. Um deles, por exemplo, Leonardo Leal, que meus pais perderam totalmente o contato, depois passou a frequentar a minha casa, depois dos anos 80 . Então, isso para mim era uma coisa completamente impensável. Como se fosse um morto que voltou. 
Então, foi de alguma forma apaziguada toda aquela sensação de saudade daquele desaparecido, mas, em outro sentido, para os outros, aquilo estava muito presente. Para os que frequentavam a minha casa e conversavam comigo, eu fui capturando tudo isso e fui guardando comigo, como se aquela saudade de gente que eu não conhecia também fosse minha, uma saudade incômoda, completamente incômoda. Porque não era saudade de morto, era saudade de morto vivo. É muito pior. Mas, como lidar com isso nas artes visuais? Então, eu tracei uma espécie de plano, e aí, o fato de ter uma formação em ciências da natureza me ajuda nisso. Desencadear um processo, uma fenomenologia, assim, da obra que passa por métodos. Métodos de pesquisa, de seleção de materiais e de atuação. Um passo a passo, uma espécie de lógica, mesmo dentro disso que é vaporoso, o mistério da criação artística.

E aí eu pensei, bom, isso vai ser a matéria, eu vou estudar sobre isso, e obviamente caí nos estudos portugueses, cai no sebastianismo, na eterna espera, numa coisa que é extremamente nordestina, que está na música, está na xilogravura, na cultura popular, no cordel, então, tudo isso já fazia par- te da minha cultura. Munido disso, eu fui tentar achar um lugar onde trabalhar essa... Eu ia fazer o que? Sair por aí cavando? Procurando desaparecidos políticos? Resolvi, então, fazer uma espécie de chamamento, quase que um pequeno manifesto, onde eu tentei capturar ali, de alguma forma, essa saudade, se era para ser uma saudade que fosse exatamente essa, dos desaparecidos políticos.

Vejo que isso foi antes das comissões da verdade, da abertura de todos os arquivos, era um momento bem difícil de tratar disso com as pessoas. Então, eu não sabia se ia dar certo e muito menos se eu teria força para fazer.

Começou pequeno, aquela coisa calada comigo mesmo, ali pensando, procurando livros e lendo em um ou outro texto, fazendo uma espécie de vocabulário, bem difícil de fazer. Vocabulário, por exemplo, de tortura, vocabulário da própria morte. Do ponto de vista biológico, para mim, já é um pouco familiar, por causa da minha formação em paleontologia. Então, acompanhar, digamos, esse processo de decomposição, de pensar no corpo mesmo, na matéria ligada à morte. 


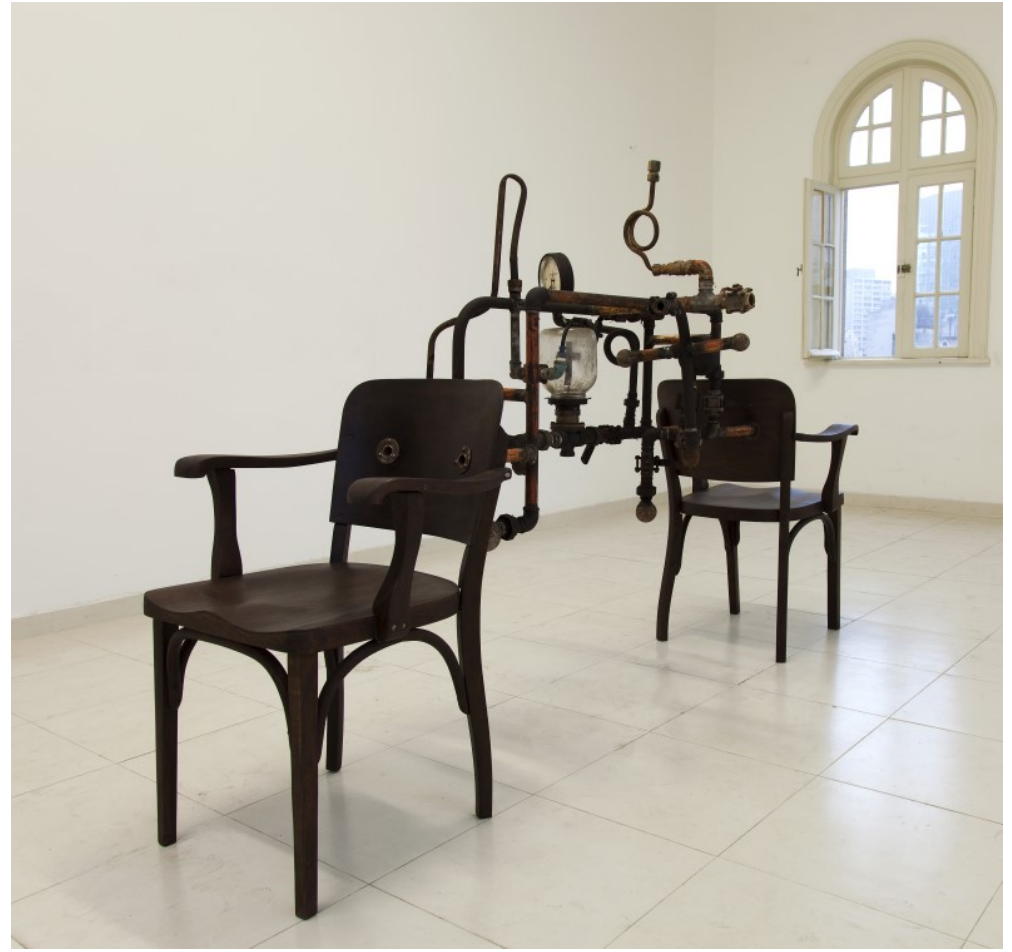

Fig. 1 - José Rufino, Intentio animae, 2012.

(Foto: Flávio Lamenha) 
E isso tudo foi se juntando... então eu criei uma linha de pensamento. Eu iria fazer o que? Sudários de corpos desaparecidos, então eu precisava encontrar pessoas que guardavam essa sensação e pedir: "Olha, traz pra aqui, vamos usar papéis que vocês próprios vão fornecer, contaminados com essa sensação de saudade." Alguns diziam que eu era louco; "Como é que você quer um papel contaminado com essa sensação de saudade, dessa pessoa que é meu irmão ou pai?" "Esses documentos nem existem. A gente queimou tudo. Você ainda quer o que está com isso impregnado?"

A ideia, então, era fazer esses sudários, como se fosse o sudário de Cristo, cujas manchas são, para os crentes, as manchas de contato com esse corpo. Para os não crentes, como eu, apenas um motivo para a gente pensar no corpo. E a obra foi então chamada de Plasmatio, como se eu quisesse plasmar essa matéria que não estava ali colocada. Obviamente esse documentozinho que eu fiz eu mandei para a Anistia Internacional, Grupo Tortura Nunca Mais e eu tentei fazer contatos, muito pessoais, não institucionais.

Alguns foram extremamente difíceis, não me receberam, não responderam. Outros, não só entenderam o trabalho que não era, por exemplo, uma homenagem, não era uma sala de desaparecidos, não era uma iconografia dos desaparecidos, mas era um lugar de chamamento para a questão. Para chamar através de um ambiente de arte, ou seja, uma cápsula de emoção para um problema nacional que não estava sendo encarado.

Alguns me ajudaram muito, por exemplo, em Recife o jornalista e poeta, Marcelo de Mário Melo. Que não só me ajudou, como usava a própria casa dele para chamar pessoas que eu entrevistava, para pedir esses materiais e eventualmente fazer essas manchas com eles. Eu não consegui fazer nenhuma com as pessoas, tive que levar os papéis e produzir depois sozinho. Porque, criava-se ali um ambiente tão difícil que não dava nem para se mexer, era impossível fazer essa etapa que seria uma espécie na minha cabeça, quando eu via, era como se eu quisesse fazer, com as pessoas, velórios, uns ritos de passagem. Então, muita gente não só não entendeu como se sentiu até agredido, com essa invasão da intimidade.

Não foram todos que entenderam o processo, que era um processo de arte. Alguns achavam que eu não tinha direito, por não 
ter tido a experiência na carne; "Então, você é muito jovem. Não foi torturado, como é que vai saber trabalhar esse assunto?" Tudo isso aconteceu durante o processo, foi perigoso para mim, porque eu tinha que encontrar esse lugar também de não tomar partido. "Isso aqui é certo. Contra o errado. Eu sou o bom contra o mau." Encontrar ali os aspectos éticos, conceituais, filosóficos, estéticos e psicanalíticos que é uma coisa complexa, a gente sabe, relação entre tortura, torturador e torturado, tudo se transmuta.

Tudo muda. Eu só entendi isso nessas leituras, nessas vivências, nessas experiências. Às vezes, quando te digo de desconfiança, de aridez e às vezes, o contrário, de completo desmoronamento emocional, parecia filme às vezes.

Encontrar, por exemplo, no Rio uma pessoa que marcou em vários lugares comigo, como se aquilo fosse um filme policial e depois quando encontra se desmancha completamente, entregava, por exemplo, fotografias de pedaços de corpo. Então, tudo isso eu tive de experimentar durante o processo da obra. Depois virou essa instalação com móveis, a estrutura física da obra lem- bra um pouco aparatos de tortura, pau de arara, por exemplo.

Às vezes, lentamente vem um texto lido, um relato, por exemplo, em formato de um banco e foi isso que eu tentei fazer... instalação tem cheiro de jasmim, é meio obscura, você entra ali e é levado a se aproximar desse lugar de desaparecimento.

Durante a Bienal de São Paulo, uma pessoa deixou um depoimento escrito, dizendo que achava que não existia desaparecimento político no Brasil, que aquilo era invenção e que lá dentro da instalação de Plasmatio tinha levado um soco no estômago. E não só isso, tinha virado cúmplice, porque tinha pegado, inclusive tinha tocado nos papéis originais, ou seja, na fala de um dos desaparecidos. Então, acho que isso sempre foi uma característica do meu trabalho.

Além de ter uma espécie de... Está imantado ali, com espíritos de coisas que aconteceram... a própria matéria resultante disso está presente, não são fotografias de algo, não é uma obra feita "pelada" do passado, o passado vem impregnado junto. Como paleontólogo, então, são esses fósseis insistindo em se tornar vivos. 


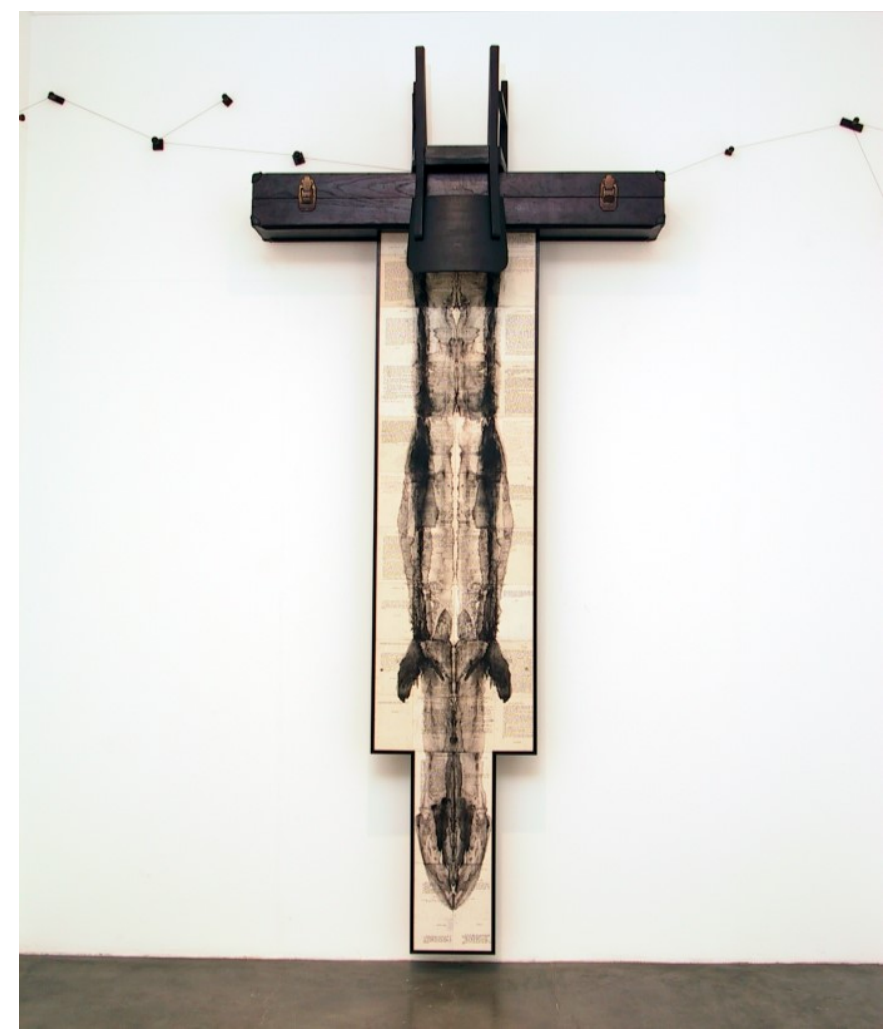

Fig. 2 - José Rufino, Plasmatio, 2002.

25 a Bienal de São Paulo, São Paulo

(Fonte: http://www.joserufino.com) 
O Plasmatio foi exposto em 2002 nessa Bienal de São Paulo. Depois, já com curadoria de Moacir [dos Anjos] foi para o MONCuritiba e veio para Recife, para o MAMAM na mesma configuração, quero dizer, com as mesmas peças, como se o processo tivesse se encerrado. Porque na realidade exigiu de mim uma coisa muito forte, assim, quase que eu fui exaurido. Por essas questões já colocadas, era muito difícil de falar, uma coisa que eu tinha que enfrentar, o próprio pânico diante das coisas.

Não me sentia ainda com a capacidade, digamos, de tratar o assunto especificamente por falta de leitura, enfim, de conhecimento. Tratar de grupos que, por exemplo, não conhecia, sabia uma sigla e não sabia o que significava. Então, tudo isso estava acontecendo naquele momento.

Depois, o Luiz Guilherme Vergara me convidou para fazer uma exposição no MACNiterói, e acho que foi em 2005 ou 2006, me pediu para, além disso, reativar o Plasmatio. Eu tinha contado uma coisa a ele, sobre uma pessoa que eu tinha tentado encontrar em Niterói, Lúcia Alves, filha de Mário Alves, o primeiro desaparecido político do Brasil, oficialmente, dado como desapa- recido no começo dos anos 80 . Fiz esse contato com ela e consegui encontrá-la finalmente; ela mora em Niterói e foi uma pessoa importante para mim naquele momento e para o resto da vida.

Pela força que representava, por tudo aquilo que guardava "ali dentro", pela luta pessoal dela com a mãe, que se chama Dilma, para encontrar enfim, o corpo do pai. Ela junto com a mãe fez um périplo, tentando oficialmente receber esse corpo que tinha, enfim, ido para algum lugar. Eu terminei recebendo dela documentos sobre a própria tortura que o pai sofreu e esses documentos foram colados, eu fiz um desses sudários para essa exposição do MAC, e eles foram colados em uma mesa que é uma mesa de massagem terapêutica hospitalar, que tem uma lixeira embaixo.

Então, esse sudário pertence hoje a coleção do MAC-Niterói, foi desmembrado da instalação Plasmatio. Lúcia não só me recebeu, como conversou com a gente, gravou depoimento sobre tudo isso. Ela esteve presente na abertura da exposição. E depois, inclusive, me chamou para eventos lá no Rio, ligados a desaparecidos políticos; o trabalho criou então outra dinâmica, ele 

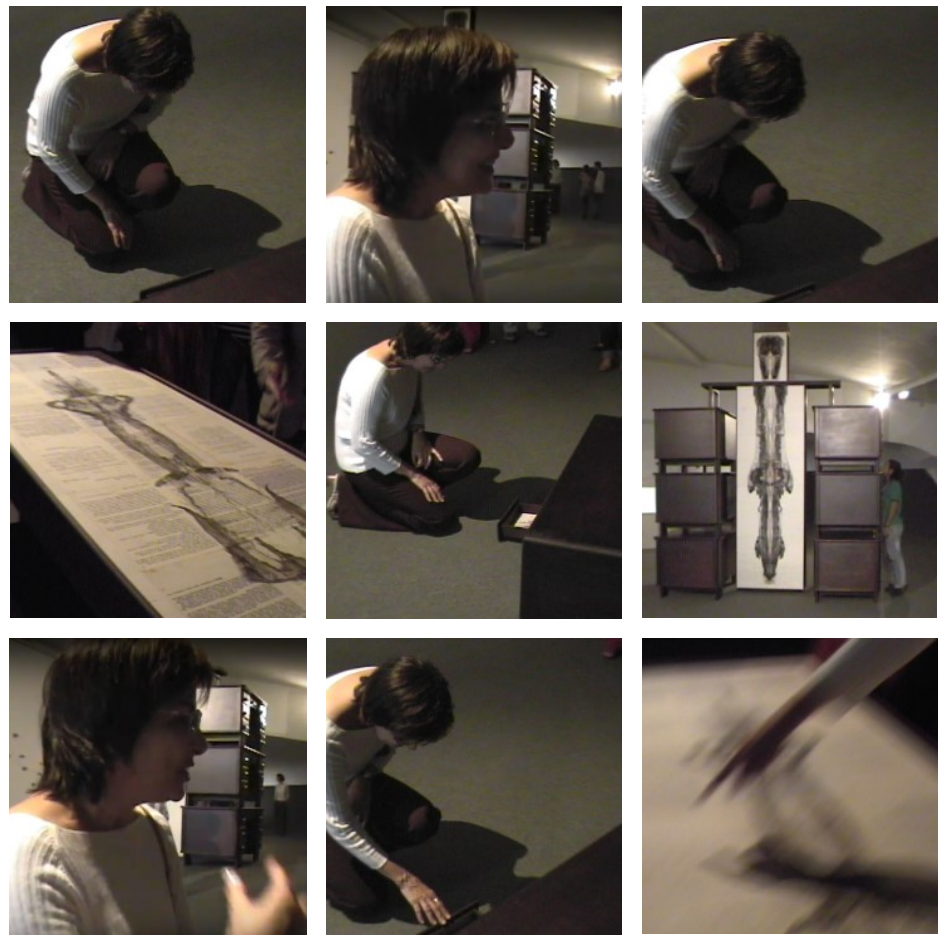

Fig. 3 - Imagens coletadas do vídeo produzido pela curadoria do Museu de Arte Contemporânea de Niterói no dia da inauguração da exposição Incertae Sedis, de José Rufino, em $15 / 10 / 2005$. As imagens registram o primeiro encontro de Lucia Alves com as obras Plasmatio, realizadas a partir da doação de cartas do arquivo pessoal da família, documentos oferecidos em confiança total de Lucia Alves ao artista e sua relação com o MAC-Niterói. A doação continha a correspondência de Mario Alves, jornalista preso e torturado até a morte pela repressão militar. Lucia Alves é filha de Mario Alves, além de uma das lideranças nacionais do movimento Tortura Nunca Mais à época da mostra. (Fonte: Arquivo pessoal de Luiz Guilherme Vergara) 
aconteceu lá na abertura da exposição como uma performance, pela presença dela passando a mão em cima dessa gravura, dizendo que aquilo era o pai. Então, conseguiu passar por esse... ou seja, achou um lugar para fazer esse rito, essa entrega, terminou me entregando, digamos, aquilo que ela achava que era exatamente a coisa mais próxima desse corpo sumido.

Fez esse processo que eu queria, digo, de materialização muito mais do que qualquer outro, num processo como um todo. $E$ isso foi importantíssimo, ao mesmo tempo me assustou muito, parecia que depois eu teria que continuar sempre. Então, eu diria a você que o Plasmatio nunca acaba, é um processo, sou eu que de vez em quando me desvio para outros formatos, para pensar de outras maneiras, mas o processo continua vivo, posso ainda retornar e refazer. Alguns grupos, por exemplo, com as pessoas ligadas ao Araguaia, que não quiseram me encontrar naquele momento, muito possivelmente agora teriam outra leitura, outra ótica do trabalho. Pelo fato de não ter essa iconografia, essa nomeação, o trabalho não trata um por um, são todos um só corpo, essa sensação. Então, por isso que ela termina saindo da pessoa e vai para os outros.
Hoje em dia, por exemplo, a gente tem uma quantidade imensa, não sei... ० Brasil talvez seja um dos países que mais tem desaparecidos de todas as categorias da violência urbana e da violência política atual...

\section{Notas}

\begin{abstract}
${ }^{1}$ A entrevista concedida por José Rufino integra o vídeo Arte e Autoritarismo (54'59"), da série História da ditadura: novas perspectivas, coordenada pelo historiador Paulo César Gomes. Entrevista conduzida a Paulo César Gomes; edição de Rafael Righez. A transcrição da entrevista foi realizada por Gabriela Bandeira, integrante do Grupo de Pesquisa Interfluxos Contemporâneos Arte e Sociedade (UFF).
\end{abstract}

